\title{
Flexible Positions, Managed Hopes: The Promissory Bioeconomy of a Whole Genome Sequencing Cancer Study
}

\author{
Rachel Haase ${ }^{a, c}$, Marsha Michie ${ }^{b, c}$, and Debra Skinner ${ }^{a, c}$ \\ aDepartment of Anthropology, University of North Carolina, Chapel Hill, NC \\ bInstitute for Health \& Aging, University of California San Francisco \\ ${ }^{\circ}$ Center for Genomics and Society, University of North Carolina, Chapel Hill, NC
}

\begin{abstract}
Genomic research has rapidly expanded its scope and ambition over the past decade, promoted by both public and private sectors as having the potential to revolutionize clinical medicine. This promissory bioeconomy of genomic research and technology is generated by, and in turn generates, the hopes and expectations shared by investors, researchers and clinicians, patients, and the general public alike. Examinations of such bioeconomies have often focused on the public discourse, media representations, and capital investments that fuel these "regimes of hope," but also crucial are the more intimate contexts of small-scale medical research, and the private hopes, dreams, and disappointments of those involved. Here we examine one local site of production in a university-based clinical research project that sought to identify novel cancer predisposition genes through whole genome sequencing in individuals at high risk for cancer. In-depth interviews with 24 adults who donated samples to the study revealed an ability to shift flexibly between positioning themselves as research participants on the one hand, and as patients or as family members of patients, on the other. Similarly, interviews with members of the research team highlighted the dual nature of their positions as researchers and as clinicians. For both parties, this dual positioning shaped their investment in the project and valuing of its possible outcomes. In their narratives, all parties shifted between these different relational positions as they managed hopes and expectations for the research project. We suggest that this flexibility facilitated study implementation and participation in the face of potential and probable disappointment on one or more fronts, and acted as a key element in the resilience of this local promissory bioeconomy. We conclude that these multiple dimensions of relationality and positionality are inherent and essential in the creation of any complex economy, "bio" or otherwise.
\end{abstract}

\footnotetext{
(c) 2015 Published by Elsevier Ltd.

Corresponding Author: Debra Skinner, Center for Genomics and Society, University of North Carolina at Chapel Hill, 347b MacNider Bldg., CB\#7240, Chapel Hill, NC 27599-7240, 1-919-966-4571 (office)/ 1-919-966-7499 (fax) debra.skinner@ unc.edu (D. Skinner).

Publisher's Disclaimer: This is a PDF file of an unedited manuscript that has been accepted for publication. As a service to our customers we are providing this early version of the manuscript. The manuscript will undergo copyediting, typesetting, and review of the resulting proof before it is published in its final citable form. Please note that during the production process errors may be discovered which could affect the content, and all legal disclaimers that apply to the journal pertain.
} 


\section{Keywords}

United States; bioeconomies; biovalue; whole genome sequencing; cancer; positionality; researchclinical care boundary; translational genomics

\section{Introduction}

Genomic research has rapidly expanded its scope and ambition over the past decade, promoted by both public and private sectors as holding the potential to revolutionize medicine through the diagnosis and treatment of disease, personalized medicine, and preventive care (Green et al., 2011; Guttmacher \& Collins, 2005). Visions of a genomic future of faster and more accurate diagnoses and more targeted treatments fuel large investments of time, money, and emotion on the part of many stakeholders, including biotech companies, researchers, patients and their family members, and the general public. However, while there has been rapid progress in genome technologies and knowledge - for example, the use of sequencing for the diagnosis of rare disorders (Yang et al., 2013) - it is still a nascent field, as yet unable to interpret much of the information generated because of technological, database, and knowledge limitations (Timmermans, 2014). Yet while the wide-ranging promises of genomics for personalized medicine and clinical care are far from being realized (Evans et al., 2011; Manolio et al., 2013), belief in the potential of genomic medicine for health care, and the investments driven by that belief, remain largely undiminished (e.g., Carlson, 2013; Carrel, 2014).

Against this backdrop, particular emerging technologies have given rise to what Martin, Brown and Turner (2008) term "promissory bioeconomies," in which "hope itself is being capitalized as the basis of commodity value" (p. 127). Research on promissory technologies (e.g., stem cell, cord blood banking, and gene therapy) has often focused on the role played by public discourse, media representations, and large-scale capital investments in fueling "regimes of hope" (Martin, Brown \& Turner, 2008; see also Brekke \& Sirnes, 2011; Petersen \& Seear, 2011). In the context of expansionary hopes and hype, biological specimens (e.g., stem cells, blood, DNA), as they are technologically reformulated as information, come to have "biovalue," a concept Waldby (2000, p. 33) defines as whatever is "generated wherever the generative and transformative productivity of living entities can be instrumentalized along lines which make them useful for human projects" (see also Waldby \& Mitchell, 2006).

However, for promissory bioeconomies of this sort to function at the scale of capitalization, public and professional buy-in, and media hype, they rely at least at present on the creation and maintenance of more local networks of non-monetary exchange, trust, personal care and obligation that are fostered through multidimensional relationships. Novas (2006), drawing on his research on patient organizations and alternative forms of capitalization in the context of genetic diseases, emphasizes the connections between these two scales of the bioeconomies of genomics, and insists that we take into account the actions of the people whose very hopes for survival are closely bound up with the materialization of such promises and their relationships with the professionals whose work embodies that hope. 
Studies of the more intimate zones of activity underpinning the complex economies of genomic medicine have illustrated how relationships between researchers and research participants shape their hopes and expectations (e.g., Hallowell et al., 2010), and also drive investments of money, time and other types of capital. For example, Hoeyer's (2003) longterm research on UmanGenomics, a company with commercial rights to Sweden's national biobank, provides a rich context for describing how both personal and institutional relationships shape practices of donation and informed consent. Hoeyer argues that the preexisting relationships - both personal and institutional - between donors and the nurses who drew samples for the biobank, were more influential in shaping donors' decisions than were the informational materials provided (see also Hoeyer \& Lynöe, 2006). Further, the expectations engendered by these pre-existing relationships both implied and were implied by historically and personally recognizable relational positions: most centrally, those of state/citizen, and nurse/patient.

In this paper, we examine a similar set of relational positions driving investments in the amorphous but rapidly expanding bioeconomy of whole genome sequencing (WGS). Our setting is a university medical center where a clinical research project recently took place that employed WGS and microarray analysis to identify novel cancer predisposition genes in families at high risk for cancer. In this project, genome sequencing was a key technology on which hopes and concerns drew together two groups of local investors (researcher/clinicians and research participant/patients) in an enterprise to build new technological presents and futures. Like Hoeyer and Lynoe (2006), we view relationships - both personal and institutional - as fundamental in shaping the expectations of both participants and researchers. However, we also wish to emphasize the multidimensional nature of these relationships in this particular setting, and the ways in which the multiple relational and affective positions occupied by researcher/clinicians and participant/patients influenced project goals and encouraged flexibility in their understanding of what constituted a "meaningful result." We examine how both parties used this flexible positioning to negotiate uncertainty and possibility, managing expectations while fostering "reasonable" hopes.

\section{The Study}

This study was conducted as part of the larger "Whole Genomic Analysis of High Risk Cancer Families Study" (HRCS). The stated aim of the HRCS was to identify novel cancer predisposition genes through WGS and microarray analysis of patients seen in the university hospital cancer clinic and selected relatives suspected to have a hereditary cancer syndrome. Most patients had previously undergone clinically available genetic testing, but with no genetic mutation identified. Of the 186 participants in the larger HRCS, three-fourths were referred due to breast and/or ovarian cancer, about one-fifth because of colon cancer/ polyposis, and a few because of other cancers. Almost all of the participants had been seen clinically before study enrollment by at least one of the HRCS researchers. Participants were told that they would be contacted if WGS revealed the genetic cause of their condition. We (the authors) were invited by HRCS researchers to conduct in-depth interviews with a subset of these participants about their understandings and experiences related to WGS and the HRCS. We telephoned individuals who indicated their willingness to be contacted for the interview study and who were representative of the larger sample. We obtained consent 
from the first 24 individuals who agreed to be interviewed. Table 1 depicts the demographic characteristics of this sample.

We conducted semi-structured telephone interviews with participants from October 2010 through October 2011. Interview questions elicited participants' understandings of WGS and the HRCS study, perceptions of the risks and benefits of participation, motivations for participating, expectations for return of results and other study outcomes, and overall evaluations of their experience with the study. We also interviewed the three HRCS researchers who had direct contact with the participants (two clinical geneticists and the genetic counselor who served as the HRCS study coordinator) about their overall goals, hopes, and expectations for WGS and the study; perceptions of possible benefits and risks; and how they perceived their relationships with participants. Interviews averaged one hour and were digitally recorded and transcribed. The interview study and the HRCS were approved by the university IRB.

For this study, analysis of interview data focused particularly on how researchers and participants viewed the value and nature of their investment in the HRCS. We reviewed each transcript to gain a holistic sense of the range and dimensions of the meanings of the responses. We then generated a coding scheme through an iterative process that is standard for content analysis (Miles, Huberman, \& Saldaña, 2013; Patton, 2002). Codes were based on the specific topics elicited by interview questions (e.g., understandings, hopes, expectations, risks, benefits, goals of WGS/HRCS). The first author used Atlas.ti to code the transcripts for these topics. Responses related to each code (e.g., benefits of study participation) were collated for each interviewee, summarized, and recorded in a data display matrix to aid in systematic comparison (Miles et al., 2013). The authors' analysis of these responses followed procedures derived from abductive and grounded theory (Charmaz, 2006; Tavory \& Timmermans, 2014; Timmermans \& Tavory, 2007). This led to findings related to each specific topic, but also to an overarching interpretation of the importance of flexible positionality in local productions of a promissory bioeconomy. In this account, we first describe the histories that participants and researchers brought to the study, including the relationships between members of each group, and show how these histories made possible a flexible positioning that is not always a feature of researcher/participant relations. Second, we examine the variety of types of investments made by each group, defining investment as including not only monetary or material resources, but also the time, social capital, and emotional labor contributed. Third, we discuss the variety of types of biovalue these investments helped to create, highlighting in particular the value that participants and researchers placed on genomic information as a gift, in addition to its potential future valuation as a commodity.

\section{Flexible Positionality}

Anthropologists and other scholars of human interaction have long emphasized the importance of attending to the various roles people adopt in different situations, stressing the dynamic nature of identifications as particular types of people and as members of specific collectives (Castells, 1997; Heath, Rapp, \& Taussig, 2004; Holland et al., 1998). Whether referred to as "roles," "identities," or "positions," what is important is not simply the 
multiplicity of such positions available, but the multiplicity of relationships they imply. In this analysis, we point to the salience for both researchers and participants of their different positions within the context of the HRCS. For participants, both the position of patient and that of family member were of high importance, along with that of research participant; while for researchers, the position of clinician (physician or genetic counselor) also figured heavily in structuring their experience of, and orientation to, the study.

Integral to participants' experiences in the HRCS was that the vast majority had at some point in their lives been diagnosed with cancer or precancerous symptoms, and all had a family history of cancer. At the time of the study, most participants had been treated for cancer, some were still actively undergoing treatment, and almost all were vigilantly following screening protocols. Their experiences as cancer or "pre-cancer" patients influenced their perceptions of the HRCS, its goals, and potential benefits. They were motivated to join the study to see if WGS could reveal the molecular cause of their cancer.

Even though the HRCS team informed them that the odds of finding the genetic cause of their cancer was low, participants viewed the research as a natural continuation of their search for answers and saw WGS as being little different from other testing except that, as part of a research study, it was free. For example, Laura (all names are pseudonyms), who had atypical breast cells and a cousin with breast cancer, recalled being very excited to join the study so she could continue her search for the cause of her family's breast cancer: "I had been tested, and my cousin had been tested, and it appeared that we did not have BRCA1, BRCA2, and it looked like our research [i.e., our search for a diagnosis] would pretty much end because of the financial responsibility that it would personally be if I did continue."

Laura, like others in the study, did not draw clear lines between her prior clinical experience and the research context of the HRCS in her search for diagnostic answers. Allison also described her entry into the study as a logical extension of her clinical experience:

I remember [the study coordinator] telling me at the time that they had come up with maybe some kind of new testing, newer than when I had first come to [the university] because in the beginning they couldn't definitely diagnose me with a polyposis, but I was hoping that with this they could come even closer.

Participants' positions as family members were also motivating, as they wanted to find the cause of their past, present, and imagined future relatives' cancers. Many drew on experiences of their own cancer or those of their parents or siblings to describe the ways they envisioned their relatives potentially benefiting from the study. Angela, who had survived breast cancer, spoke about the difficult choice she had been contemplating in regard to a prophylactic hysterectomy, and linked this to the decisions her daughters might someday need to make. "Being part of the study," Angela explained, "has been a real opportunity for me to do what I can to empower myself to learn things that I can use in my own life and pass along to both my daughters as far as ways that they should live and choices that they should make to decrease their chances of getting it." Angela also noted that her daughters were both willing participants in the HRCS because, as she described, they had "seen what I've been through. They've seen what I went through when my mom had it twice, and they've been there as far as seeing what cancer can do to a family." 
Participants' willingness to join the HRCS was enhanced by their pre-existing clinical relationships with one or more members of the research team and the university medical system of which they or their relatives were a part. They expressed personal trust in the research team as well as a high degree of confidence in the university as an institution. Lucy, who had a personal and family history of colon cancer, said, "I trust the folks there. They've always been straight with me and telling me just like it is." Similarly, Jennifer, who had been treated for breast cancer by the HRCS researchers in their role as clinicians, described how this previous relationship influenced her to join the study:

When she [the study coordinator] called me, it was someone - I've met her face to face. So I had a relationship. It wasn't like some stranger calling me out of the clear blue saying, "Would you be interested in being in this study?"

In some cases, participants' feelings toward both the university and the HRCS researchers went beyond trust, toward something akin to obligation as Jennifer expressed: "They were so wonderful to me when I was a patient...I would have done anything to have helped them." By "obligation," we are not implying that the participants felt pressured or coerced to participate in the study. Indeed, they viewed the HRCS as a fortuitous opportunity, and they perceived their participation in part as a chance to give back to the clinicians who had helped them and whose research they identified with at a personal level. They had a sense of being a "research participant" in a real and active way, in large part because of their prior and present experiences as patients receiving clinical care. Jennifer, like other participants, spoke as if she were a member of the research team rather than a passive subject, referring not to "they" the researchers, but to "we" the team of people trying to help the next generation. Martina, who had a history of colon cancer, explained, "We're kind of all in this together trying to figure this out."

Researchers' perspectives on their hopes for, and obligations to, participants were similarly filtered by their previous clinical interactions. Ms. Roberts, the genetic counselor and HRCS study coordinator, spoke at length about her ongoing relationships with the participants. She knew many of them well and had watched them struggle emotionally, blaming themselves for their disease and pondering what they might have done to cause it. She believed that finding the genetic cause would go a long way toward alleviating this emotional burden:

Whatever they've done in their life they've sort of blamed, or they've racked their brain trying to figure out what it was. So I think having another cause that they know they had no control over, or very little control over, is helpful in getting that answer for them.

Dr. Charles, the principal investigator of the HRCS, also talked about the effects of preexisting clinical relationships on both his and participants' approaches to the study. Although he stressed he did not know most participants like their general practitioner would, he described how being there with them at "critical junctures" in their lives led to a deep, if circumscribed, awareness of their travails, and like Ms. Roberts, described in some detail the emotional struggles he saw participants deal with regarding their genetic legacy.

All three HRCS researchers expressed a strong desire to provide diagnostic answers for the participants and their families. Although they were sensitive to their obligations as 
researchers - for example, expressing deep concern that participants understood the study, its risks and benefits, and the unlikeliness of finding the genetic cause of their condition they nonetheless appeared to think of the participants first and foremost as patients in search of answers, and they reckoned the project's success in terms of providing a personal answer as much as in more scientific terms of finding novel disease-causing variants. This is apparent in Dr. Charles' explanation of how the study began:

We've been keeping track of patients now for seventeen years who we have been seeing in the cancer genetics clinic, and we will have patients...whom we are unable to give an answer... So we've been keeping track of those patients in a database for a long time with the hope that someday we'd be able to address it.

In the interviews, all parties shifted between different relational positions as they managed their hopes and expectations for the research. These positions also shaped their investments in the project and their valuing of its possible outcomes - all key elements in the creation of this local promissory economy.

\section{Investing in hope}

Our conceptualization and analysis of researchers' and participants' views of their investment in the HRCS include both monetary and material contributions as well as the time, social capital, and emotional labor expended. . Participants viewed giving a blood sample as a simple investment that could reap potentially large rewards. When asked the most important thing that people should consider when deciding to participate, Laura replied:

How very easy it is for the people giving the blood, giving the samples. It's just a venipuncture really and a little paperwork to be involved. It's no invasion. It doesn't upset your life at all, and yet you might be able to get back great, wonderful information for your family.

Participants did not experience the basic requirements of study participation as greatly onerous; nor did they expound on the other types of labor in which many of them engaged, such as time spent recruiting relatives to join the study. Researchers had communicated that the participation of multiple relatives was essential to the task of identifying cancer risk genes, and participants expended effort and utilized their own social capital within their families to recruit them. Those who ended up recruiting numerous relatives expressed pride and satisfaction in doing so, while those who were unable to persuade relatives to participate expressed deep disappointment.

The researchers also spoke about what they viewed as investments on the part of participants, again framing these in the context of pre-existing clinical relationships. Dr. Charles noted that the clinician-patient relationship set the stage for obligations and expectations on both sides that differed from what he described as the more "contractual" relationship found in purely research studies where such relationships mostly do not exist. He explained:

I think when you start taking care of somebody, and you've touched them, literally touched them ... it definitely changes that relationship, and it's less contractual and 
more intimate and more serious with expectations on both sides. They expect you to help them, and you expect - what do you expect from them that you don't expect from a (research) subject? I guess an investment, and I guess there's an expectation of trust.

Ms. Roberts also talked about her strong sense of obligation to the HRCS participants, especially to those who had demonstrated their investment by convincing relatives to join the study:

I want to find something in all the families, but there are some families that you do get more attached to just because they've gotten all of these relatives to participate, and they have so much invested. ... You'd really like to be able to help them just because you know they are so invested in it.

We also include as forms of investment participants' willingness to take what some perceived as significant risks, including offering up their own biological material for research (see also Waldby, 2002). Most participants were unconcerned with the risks of the study, such as privacy issues related to genetic information. A few, however, viewed their donation of blood as a significant act with some potential harm involved. For example, Candice, who had a family history of breast cancer, worried that information uncovered during the study might affect her health insurance, and Lucy raised the possibility that genetic testing could result in unpleasant surprises regarding paternity or adoption. Though these and other possible risks were acknowledged, participants were motivated to join the HRCS to find an answer for themselves and their families and to contribute to the scientific enterprise. These potential benefits justified their investment and outweighed any concerns.

The researchers had also invested large amounts of time, money, emotion, and social and professional capital in the study, although Dr. Charles noted that this was typical for all research. As mentioned above, they had collected, over more than a decade, the names of potential participants, with the hope that they might one day be able to provide answers for them. Dr. Charles, the lead researcher, noted in an interview that he had "a grant that I got a few years ago that still had some money on it," which he was able to direct toward the HRCS. He and other researchers, he explained, had attempted a similar project several years earlier, but the state of the technology had presented a barrier, so he had held onto the grant money in anticipation of a better opportunity. The HRCS study then represented the culmination of that hope, and the researchers' professional identities were very much bound up in conducting the project. Dr. Charles also acknowledged certain risks to himself and the research team. Although he rated it as unlikely, he noted that if there were to be a security breach (as had recently happened elsewhere within the university), he personally could be held responsible by the administration.

\section{(Bio)value: information, results, and knowledge}

These kinds of investments by both researchers and participants led to a form of biovalue central to both parties: "information." In elaborating her definition of biovalue as a "yield of vitality produced by the biotechnical reformulation of living processes," Waldby (2002, p. 310 ) noted that both use value and exchange value are pertinent to its valuation. Where 
classical Marxist theory defines exchange value strictly as a commodity price, we, like Waldby, emphasize that even in bioeconomies embedded in capitalist systems, biovalue is exchanged not solely as a commodity (although often, of course, it is), but also as a gift as we discuss below.

Participants spoke of "information" both as something that they first gave to the researchers through their DNA sequence data and family history, and then as something that researchers returned back to them in the form of diagnostic results, which participants in turn could share with their families. Although most viewed a diagnostic result as highly valuable and desirable, the vast majority did not expect clinical benefits for themselves. Rather, they anticipated being able to pass this information to family members, for whom clinical utility might be more likely in terms of preventive strategies or future therapies. For example, Diane, who shared with her family a history of polyposis, said: "If something did show up ... it would be something that I could share with [family members] as sort of a warning to them to stay on top of this, and make sure that they don't miss their colonoscopies and/or to get started taking them earlier."

Participants often talked about WGS results as a gift that they could bestow upon their families. Laura understood the HRCS as "probably giving your family - the family in the future, your children, your grandchildren - power with the knowledge that can come from this." Knowledge, then, was a form of information created by the researchers through the analysis of many participants' information, but could also be re-converted into results specific to one individual or family. For example, Luke, who had a family history of polyps, said that his main motivation for study participation was "furthering human knowledge." However, he also wanted to learn "information" about himself.

Researchers' valuing of the study largely paralleled these distinctions. Dr. Charles described two goals for the HRCS:

I think there are two very related goals ... on one hand the discovery of novel genes that are involved in cancer pre-disposition and causation. ...The other major goal of the study is to give some patients ... concrete tangible insight into what it was or what it is that is causing the cancer pre-disposition in their family so that their family members could take immediate and useful measures for prevention.

This explanation provides food for thought in relation to both types of valued information. Dr. Charles advances the possibility of providing personal genetic results, or "answers" to some participants, not as a potential bonus - a welcome side effect of a study oriented toward the production of generalizable knowledge - but as an equally important goal. Recall that participants were "collected" over years into a database of patients for whom Dr. Charles and Ms. Roberts wished to provide "answers." Importantly, the researchers explained that their ability to provide these answers was not premised solely on success in generating new knowledge (i.e., gene discovery). Results could also come about as a consequence of sequencing participants' genomes and finding rare variants known to be associated with cancer risk but not detectable through currently available clinical testing. Indeed, as the study progressed, at least one family's cancer was found to be linked to one of these rare variants. 
Successfully identifying the genetic variant causing a person's cancer may not provide a medically actionable course, calling into question this information's "use value." However, the value of a genetic result lies not only in its clinical utility, but also in its personal utility. Ms. Roberts strongly felt that this information would be of high personal value for the participants: they would benefit from getting an answer so that they could "put a name on it and in some cases from being able to identify a cause beyond their control, for which they could stop blaming themselves"; and they could learn more about the risks for relatives and share this with them - a primary motivation for joining the study.

This notion of family benefit poses a major challenge to the framing of the individual patient as an autonomous individual, and therefore to individualistic understandings of "benefit" from research participation. The HRCS was unlikely to provide "medically actionable" results to individual participants, but neither researchers nor participants themselves understood the individual to be the most relevant unit. For both researchers and participants, the family was the collective patient, and information gleaned from WGS had use value for this collective. Dr. Charles said simply, "The family is your patient." Dr. Hamlet noted that it did not matter whether or not a given family member had actually given a sample, saying, "Everyone in the family is kind of in the same boat, whether they're in the study or not."

For most participants, discussions of family benefit also served as a discursive bridge between the notions of "results" and of "knowledge." They acknowledged that while they hoped their own families would benefit through getting diagnostic results from WGS, they did not necessarily expect this to happen. Participants managed their expectations in this regard by a discursive blurring of "my family" with "someone's family," and by emphasizing their positioning as participants in a research study rather than as patients or as family members. As Giselle stated, "There are many, many, many families out there just like ours. ... It does benefit my family, but it also benefits the people - women - across the world." Frank, whose daughters had breast cancer, framed his hopes for the study metaphorically: "I hope that I am one little [grain of] sand in the big building that the people are building that finds ways to prevent cancer or treat cancer."

While a few participants spoke broadly of the aims of the HRCS as "fighting for a cure," they viewed the value generated by the study more specifically. Most identified improved screening techniques as a realistic near-term goal, highlighting prevention rather than treatment. Participants with a family history of breast cancer and past experiences with genetic testing for BRCA1/2, in particular, spoke of their hopes for the study to lead to new tests that would identify novel cancer-causing variants. Jennifer, who had several relatives diagnosed with breast cancer, explained:

If it's successful, it may be like BRCA1 and 2. People can be tested to know-have some information ahead of time to make a decision: "Do I have a prophylactic mastectomy? Is there some kind of treatment that can be done instead of waiting around to develop breast cancer?"

These hopes for better surveillance also surfaced in the interviews with colon cancer patients, who did not have as much experience with genetic testing but had long histories of screening. 
One major difference between participants' and researchers' understandings of the societal value of the study was temporal in nature. Whereas participants talked about the research as leading more or less directly to screening technologies with immediate clinical utility - if not for them, then for their family or others in society - researchers focused more on medium and long-term research outcomes, describing the incremental gains in knowledge that could be obtained through the application of other researchers' ideas and technological expertise to their findings. Dr. Charles emphasized that the goal of gene discovery was, in his view, "far, far down the pike." He also sounded a cautionary note in regard to the idea of "benefit":

I would say in all likelihood, like most research, the benefit will be very tiny; it'll be very incremental, and it will be very much in the long-term towards people who may have benefitted gradually from better diagnostics and better treatments.

In a second contrast, while participants envisioned benefits broadly as applying to "all women" or "all people with cancer," researchers were much more cautious in identifying beneficiary populations or hyping the magnitude of the possible outcomes. Unlike participants, who sometimes conflated this study with BRCA testing and often drew on the BRCA example as a means to frame the potential value of the knowledge produced within the study, researchers used it as a point of contrast, something their own study could not achieve. Dr. Hamlet explained:

The mythical BRCA3 would be the best outcome, but of course that won't happen because enough has been done upon hereditary breast and ovarian cancer that we pretty much know by now that BRCA1 and 2 account for the majority of families with hereditary breast and ovarian cancer, and each individual gene accounts for a smaller and smaller slice of the pie. And so we're probably at the point where a new gene that we discovered might account for the hereditary-the familial breast cancer in one percent of families or two percent of families, and we'd be lucky if we found one that was anything more than two or three percent.

Researchers' emphasis on the value of the study, then, was on the long and sometimes meandering road from blood sample to result to treatment, and the complexity of trying to solve such a multifaceted problem as "cancer." They did not envision this enterprise as one big project as did some participants, but stressed the many partial connections and contingent pathways of discovery that could at times lead nowhere. The knowledge produced by the HRCS would need to circulate far and wide to be materialized as clinical applications that would result in Waldby's "yield of vitality" - a longer life or better quality of life for someone else.

Researchers also acknowledged the (non-monetary) exchange value inherent in this knowledge. Dr. Charles candidly discussed the nature of academic research and the many kinds of prestige and acknowledgement that scientists pursue:

Everybody has conflict of interest that isn't financial. You want a promotion. You want to make full professor, and you want to publish. You want to see your name in print. You want people to talk about your research. You know we all have these venal motivations that prompt us. ... So that's absolutely a motivation. The reason I 
think it gets talked about less is, besides the fact that it flies in the face of the altruistic scientist who's trying to help humanity, is that it's also hard to quantify. It's easy to quantify conflicts of interest or just interests that are monetary. It's very hard to quantify: "I want promotion. I want my friends to think I'm a success."

Despite Dr. Charles' candid acknowledgement of the cultural and social capital that might accrue to a successful researcher, the overall emphasis in interviews with both researchers and participants was not on their individual prospects for "benefit" through the use of the information generated, but rather the need for information to circulate, and ideally, to circulate freely - in order to be of benefit. The researchers in particular stressed their strong opposition to financially benefiting from the HRCS (e.g., by patenting any genetic discoveries), while most of the participants seemed unaware of the huge commercial interests in the genetics industry. In fact, both researchers and participants spoke of the information the study would produce as a type of gift - something of value that could be given to those they cared about. Researcher/clinicians hoped to be able to give "answers" to people they knew and had cared for as patients. Participants hoped to be able to give these "answers" in turn to members of their family, including those who had not yet been born. Both parties hoped that the information they generated locally would circulate through the world of science to create "knowledge" that would benefit people around the world. While the research team, however, was well aware of the potential for private actors to attempt to control and capitalize on this circulation, research participants did not demonstrate to any significant degree an awareness that the gifts they gave freely might be transmuted into commodities for which they, their families, or "someone else's family in the future" would have to pay. The vague and somewhat naïve nature of participants' understandings of the processes by which information circulates at varying degrees of abstraction to become scientific knowledge illuminates the extent to which trusting relationships between researchers and participants shape decisions around participation. In the context of the HRCS, we do not believe this trust to have been misplaced; nonetheless, the broader implications are concerning, as we discuss further below.

\section{Discussion}

Genomic research and the creation of promissory bioeconomies around it involve multiple categories of investors in complex webs of interdependence that extend far beyond the obligations outlined in study protocols and consent forms. The HRCS provides an example of the development of a local promissory economy that emerged out of the flexible positionalities of researchers and participants and their understandings of one another's hopes and expectations for the study, which in turn motivated their investments of time, emotion, social capital, trust, and resources.

One possible structure for such a bioeconomy is found in many biobank projects. As elaborated by Tutton (2004), these projects are characterized by a type of gift economy, or at least a discourse of giving, that guides approaches to sample donation, while the valuation through exchange of information extracted from these samples rests on a far more commercialized economy (Busby, 2006; Hoeyer, 2003; Tutton, 2004). Such projects call attention to the ways in which genetic research participants may envision an abstract and 
expansive "good" that science will produce from the tissues and resulting information they have offered - a vision that genetic researchers may be disinclined (because of narrower commercial interests) or simply unable to fulfill (Hoeyer \& Lynoe 2006; Michie et al. 2011; Reddy 2007). In the context of the HRCS, however, the separation of "tissue" from "information" economies was not so strict nor the reciprocity so limited. Both "results" and "knowledge" were prized as study outcomes by participants and researchers alike, not for their commercial exchange value nor for individual use, but as gifts that needed to circulate in order to be of value. In this sense the HRCS researchers - though likely not the participants - differ markedly from those involved in more commercialized research projects. In the latter cases, some bioethicists have expressed concerns that the "gift" motivations of research participants implicitly demand an ethical reciprocation that may not be forthcoming (Hoeyer, 2003; Tobin et al., 2012).

Our findings also indicate that in large part the distinction between "research" and "clinical care" is one that is not fixed or even separable into distinct spheres of practice in studies such as the HRCS that enroll patients with a goal of discovering information potentially of both personal and scientific value (e.g., Berg et al., 2013; Foreman, Lee, \& Evans, 2013). This distinction is instead flexibly applied to manage expectations while cautiously fostering the hopes needed to promote research participation. In accord with Easter et al. (2006), we suggest that the combination of research that includes forms of clinical practice (e.g., return of results, genetic counseling, referrals) under some circumstances functions to temper unrealistic expectations on the part of researchers and participants alike, and to impart an important human dimension to technological hopes for the future. As such, this study adds to literature on the implications of returning individual research results for the research/ clinical practice boundary (Miller et al., 2008), and on the ambiguity of this boundary and the ethical responsibilities this ambiguity entails (Burke et al., 2014; Pullman \& Hodgkinson, 2006).

In the HRCS the different positions and relationships occupied by researchers and participants gave each party insight into the different facets of the study. Each had a better understanding of what a meaningful result might look like from the other's perspective than they might have had without these multiple dimensions of relation; and this insight helped each to conceptualize and invest in more than one type of value as a potential outcome of the study. Participants' positioning as research subjects, patients, and family members gave them a range of perspectives on the cancer research enterprise. Their pre-existing relationships with the researchers and the university health system also allowed them to position themselves as "part of the team" in a substantive way. While they understood their participation in part as a continuation of prior clinical testing, they were also invested in the production of more generalized knowledge about cancer in hopes that this knowledge would benefit future generations of their own families. We suggest that participants' flexible positions both limited their dependence on a therapeutic misconception that the research would benefit them directly and expanded their concept of therapeutic benefit well beyond their individual health outcomes (see Appelbaum et al., 1982; Appelbaum et al., 1987; Kimmelman, 2007). Similarly, researchers' expectations of the value that personal results would have for participants were also filtered through their prior knowledge of these participants as patients: of their medical histories of surveillance and treatment, and of their 
often equally long histories of searching for answers both for themselves and for their families. These intimate understandings and their past relationships as caring clinicians to the participants clearly shaped their hopes for what they might realistically be able to do for people, beyond the hope of "scientific progress."

Both participants and researchers positioned the family as the key unit of benefit. Most participants did not expect to benefit personally from the HRCS, but they were motivated to join the study in hopes that it could at some point provide information of use to their own, or to "someone's family." Researchers also viewed the family as immediate beneficiaries if diagnostic results were found, and as long-term potential beneficiaries of genomic knowledge. This emphasis on family further calls into question the notion of the autonomous patient/participant in genomic research, and the implications of that for consent and return of results--issues at the forefront of much debate in genomic research (e.g., Beskow \& Burke, 2010; McGuire, Caulfield, \& Cho, 2008; Wolf, 2012).

In interviews, respondents easily shifted between these positional identifications in the course of framing and managing their own hopes and expectations for the study. We suggest that this flexibility facilitated their participation in the face of potential and probable disappointment on one or more fronts, and is a key element in the resilience of "bioeconomies" more generally despite experiences of failure. Rather than viewing multiple dimensions of relationality and positionality as inherently problematic, we view this multiplicity as simply inherent and essential in the creation of any complex economy, "bio" or otherwise. Similarly, the broad and multifaceted nature of "investment" by flexibly positioned researchers and participants in this study offers an enriched understanding of the biovalue that these investments generate, both in the present and in an envisioned and hoped-for future. While based on a small, relatively homogeneous sample, our findings are suggestive and signal a need for greater understanding of the relational processes through which the possibility of obtaining clinically meaningful information from genome sequencing is constituted, interpreted, and situated by researchers/clinicians and participants/ patients within the context of other overlapping hopes, fears, expectations, and obligations.

\section{Acknowledgments}

We wish to thank the anonymous reviewers whose suggestions for revision were most helpful. The research on which this study is based was supported by the Center for Genomics and Society at the University of North Carolina-Chapel Hill, funded by the National Human Genome Research Institute (NHGRI) of the National Institutes of Health (NIH) under Award Number 2P50HG004488, and by NCGENES, funded by NHGRI/NIH under Award Number U01 HG006487-01. The content is solely the responsibility of the authors and does not necessarily represent the official views of the NIH.

\section{References}

Appelbaum PS, Roth LH, Lidz C. The therapeutic misconception: Informed consent in psychiatric research. International Journal of Law and Psychiatry. 1982; 5(3-4):319-329. [PubMed: 6135666]

Appelbaum PS, Roth LH, Lidz CW, Benson P, Winslade W. False hopes and best data: Consent to research and the therapeutic misconception. The Hastings Center Report. 1987; 17(2):20-24. [PubMed: 3294743]

Berg JS, et al. Processes and preliminary outputs for identification of actionable genes as incidental findings in genomic sequence data in the Clinical Sequencing Exploratory Research Consortium. Genetics in Medicine. 2013; 15(11):860-7. [PubMed: 24195999] 
Beskow LM, Burke W. Offering individual genetic research results: Context matters. Science Translational Medicine. 2010; 2(38) 38cm20.

Brekke OA, Sirnes T. Biosociality, biocitizenship and the new regime of hope and despair: Interpreting "Portraits of Hope" and the "Mehmet Case". New Genetics and Society. 2011; 30(4): 347-374.

Brown N. Hope against hype - accountability in biopasts, presents and futures. Science Studies. 2003; 16(2):3-21.

Brown N, Kraft A. Blood ties: Banking the stem cell promise. Technology Analysis \& Strategic Management. 2006; 18(3/4):313-327.

Brown N, Michael M. A sociology of expectations: Retrospecting prospects and prospecting retrospects. Technology Analysis \& Strategic Management. 2003; 15(1):3-18.

Burke W, Evans BJ, Jarvik GP. Return of results: Ethical and legal distinctions between research and clinical care. American Journal of Medical Genetics C: Seminars in Medical Genetics. 2014; $166 \mathrm{c}(1): 105-111$.

Busby H. Biobanks, bioethics and concepts of donated blood in the UK. Sociology of Health \& Illness. 2006; 28(6):850-865. [PubMed: 17184422]

Carlson B. DNA sequencing: The clinical potential. BioMarket Trends. 2013; 33(2) http:// www.genengnews.com/gen-articles/dna-sequencing-the-clinical-potential/4684/.

Carrel, L. [accessed 09/18/14] Illumina: Making markets by unlocking the genome. 2014. http:// news.investors.com/082214-714433-ilmn-slashes-cost-of-genome-sequencing.htm

Castells, M. The power of identity. Malden, MA: Blackwell Publishers Inc; 1997.

Charmaz, K. Constructing grounded theory: A practical guide through qualitative analysis. London: Sage; 2006.

Easter MM, Henderson GE, Davis AM, Churchill LR, King NMP. The many meanings of care in clinical research. Sociology of Health \& Illness. 2006; 28(6):695-712. [PubMed: 17184413]

Evans JP, Meslin EM, Marteau TM, Caufield T. Deflating the genomic bubble. Science. 2011; 331(6019):861-862. [PubMed: 21330519]

Foreman AK, Lee K, Evans JP. The NCGENES Project: Exploring the new world of Genome Sequencing. North Carolina Medical Journal. 2013; 74(6):500-504. [PubMed: 24316776]

Green ED, Guyer MS. National Human Genome Research Institute. Charting a course for genomic medicine from base pairs to bedside. Nature. 2011; 470:204-213. [PubMed: 21307933]

Guttmacher AE, Collins FS. Realizing the promise of genomics in biomedical research. Journal of the American Medical Association. 2005; 294(11):1399-1402. [PubMed: 16174701]

Hallowell N, Cooke S, Crawford G, Lucassen A, Parker M, Snowdon C. An investigation of patients' motivations for their participation in genetics-related research. Journal of Medical Ethics. 2010; 36(1):37-45. [PubMed: 20026692]

Heath, D.; Rapp, R.; Taussig, K-S. Genetic citizenship. In: Nugent, D.; Vincent, J., editors. A companion to the anthropology of politics. Oxford, UK: Blackwell Publishing; 2004. p. 152-167.

Hoeyer K. "Science is really needed-that's all I know": Informed consent and the nonverbal practices of collecting blood for genetic research in northern Sweden. New Genetics and Society. 2003; 22(3):229-244. [PubMed: 15115024]

Hoeyer K, Lynöe N. Motivating donors to genetic research? Anthropological reasons to rethink the role of informed consent. Medicine, Health Care, and Philosophy. 2006; 9(1):13-23.

Holland, D.; Lachicotte, W.; Skinner, D.; Cain, C. Identity and agency in cultural worlds. Cambridge: Harvard University Press; 1998.

Kimmelman J. The therapeutic misconception at 25: Treatment, research, and confusion. The Hastings Center Report. 2007; 37(6):36-42. [PubMed: 18179103]

Manolio TA, et al. Implementing genomic medicine in the clinic: The future is here. Genetics in Medicine. 2013; 15(4):258-267. [PubMed: 23306799]

Martin P, Brown N, Turner A. Capitalizing hope: The commercial development of umbilical cord blood stem cell banking. New Genetics and Society. 2008; 27(2):127-143.

McGuire AL, Caulfield T, Cho MK. Research ethics and the challenge of whole-genome sequencing. Nature Reviews: Genetics. 2008; 9(2):152-156. 
Michie M, Henderson G, Garrett J, Corbie-Smith G. "If I could in a small way help": Motivations for and beliefs about sample donation for genetic research. Journal of Empirical Research in Human Research Ethics. 2011; 6(2):57-70.

Miles, MB.; Huberman, AM.; Saldaña, J. Qualitative data analysis. 4th ed.. Thousand Oaks, CA: Sage Publications; 2013.

Miller FA, Giacomini M, Ahern C, Robert JS, de Laat S. When research seems like clinical care: A qualitative study of the communication of individual cancer genetic research results. BMC Medical Ethics. 2008; 9:4. [PubMed: 18294373]

Novas C. The political economy of hope: Patients' organizations, science and biovalue. BioSocieties. 2006; 1(3):289-305.

Novas C, Rose N. Genetic risk and the birth of the somatic individual. Economy and Society. 2000; 29(4):485-513.

Patton, M. Qualitative research \& evaluation methods. 3rd. Thousand Oaks, CA: Sage Publications; 2002.

Petersen A, Seear K. Technologies of hope: Techniques of the online advertising of stem cell treatments. New Genetics and Society. 2011; 30(4):329-346.

Pullman D, Hodgkinson K. Genetic knowledge and moral responsibility: Ambiguity at the interface of genetic research and clinical practice. Clinical Genetics. 2006; 69(3):199-203. [PubMed: 16542381]

Reddy DS. Good gifts for the common good: Blood and bioethics in the market of genetic research. Cultural Anthropology. 2007; 22(3):429-472. [PubMed: 18458755]

Tavory, I.; Timmermans, S. Abductive analysis: Theorizing qualitative research. Chicago: University of Chicago Press; 2014.

Timmermans S. Trust in standards: Transitioning clinical exome sequencing from bench to bedside. Social Studies of Science. 2015; 45(1):77-99.

Timmermans, S.; Tavory, I. Advancing ethnographic research through grounded theory practice. In: Bryant, A.; Charmaz, K., editors. Handbook of grounded theory. London: Sage; 2007.

Tobin SL, et al. Customers or research participants? Guidance for research practices in commercialization of personal genomics. Genetics in Medicine. 2012; 14(10):833-835. [PubMed: 22699154]

Tutton, R. Person, property and gift: Exploring languages of tissue donation to biomedical research. In: Tutton, R.; Corrigan, O., editors. Genetic databases: Socio-ethical issues in the collection and use of DNA. London: Routledge; 2004. p. 19-38.

Waldby, C. The visible human project: Informatic bodies and posthuman medicine. London: Routledge; 2000.

Waldby C. Stem cells, tissue cultures and the production of biovalue. Health. 2002; 6(3):305-23.

Waldby, C.; Mitchell, R. Tissue economies: Blood, organs and cell lines in late capitalism. Durham: Duke University Press; 2006.

Wolf SM. The past, present, and future of the debate over return of research results and incidental findings. Genetics in Medicine. 2012; 14:355-357. [PubMed: 22481182]

Wolf SM, Paradise J, Caga-anan C. The law of incidental findings in human subjects research: Establishing researchers' duties. Journal of Law, Medicine \& Ethics. 2008; 36(2):361-383.

Yang Y, et al. Clinical whole-exome sequencing for the diagnosis of Mendelian disorders. New England Journal of Medicine. 2013; 369(16):1502-1511. [PubMed: 24088041] 
Small-scale research studies are an underexplored dimension of genomic bioeconomies

Boundaries between research and clinical care practices are not fixed or separable

Managing expectations while fostering hope is essential to bioeconomies' resilience

"Information" is a key form of genomic biovalue, both as gift and commodity

Researcher-participant relationships shape the biovalue of genomic information 


\section{Table 1}

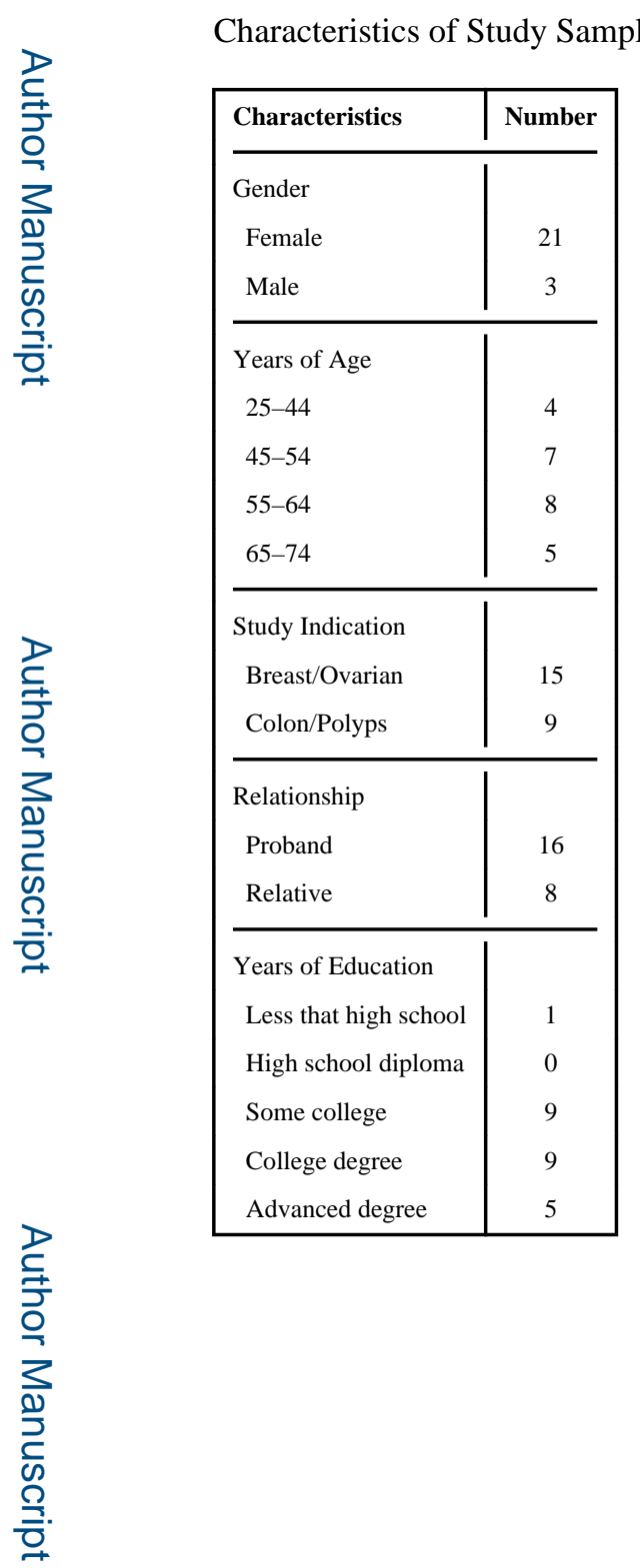

